be the prime contractor and no move seems to have been made to license the consortia of industrial companies to build the design. The AEA has already submitted tenders in Finland, and has signed a contract for the supply of information to Japan; it seems dotermined to keep the SGHWR to itself. Meanwhile, the Minister of Technology is still wondering what to do with the nuclear power industry in Britain. $\mathrm{He}$ should think quickly, before the authority answers his questions for him.

\section{Experimental Factories}

\section{from Angela Croome}

A SECOND stage in the Akademgorodok (science city) experiment in Siberia is now actively under way. This involves the development of areas outside the main centre, containing experimental factories, design offices and special training facilities to speed the transition from good idea to industrial production. The scheme was put forward by the Siberian Academy of Sciences led by Academician Mikhail Lavrentiev in 1966 and adopted by the Soviet Government last year. The site chosen is about $2 \cdot 5$ miles from Akademgorodok on the banks of the Ob Sea and is to be called Pravye Chomy. The population will be limited to $15,000-$ much less than the total of 40,000 which Akademgorodok attained last year, its tenth anniversary.

The object is to improve the ways in which basic research is turned into industrial practice. The ideas, which will come from the research institutes of Academgorodok, will pass to design offices at Pravye Chomy linked with the appropriate institute. Designs produced here will then be developed at centres on the spot which are described as "something between laboratories and factories". In these centres development will go at least as far as the production of prototypes, still under the guidance of the original inventor. Academician Lavrentier commented, "We have recently come to the conclusion that the traditional 'conveyor belt'-academic institute/design office/industry-by which scientific discoveries are brought into practical use in industry, often works too slowly. . . The Siberian Design Office experiment, whereby valuable scientific ideas are brought to the point of practical industrial use under the direct control of the inventors themselves, has proved highly successful". The Institute of Hydrodynamies at Akademgorodok has pioneered the procedure. The hydraulic impact forging techniques introduced by the institute are estimated to hav esaved the Soviet oxygen equipment industry alone 100 million roubles a year. An interesting feature of the Pravye Chomy scheme is that most of the capital cost is being found by industry.

The scheme will be mostly operated by young people. This is seen as a unique opportunity to provide, after the 3-4 year development phase, not only effective designs but the people to put them to work on the shop floor. Linked to this is the introduction of a new type of degree to be given by Novosibirsk Technical College, shortly to be opened. This qualification will be intermediate between that of the full engineer and skilled factory hand. Novosibirsk University is adding an engineering faculty soon in support of the new technological developments. A large workshop block with a floor area of 1,500 square metres is nearly ready at Pravye Chomy.

\section{French Scientists on Strike}

\section{from our Paris Correspondent}

IF French politicians of all political parties rarely show an active and informed interest in researchelection speeches contain polite but woolly references to the "progress of science" but are singularly lacking in precise policies, and the discussion over finance each year is carried on before a virtually empty Housescientists themselves seem to have long ago made up their minds to direct the attention of politicians and the Government to their future.

This is why an order to strike was given by two trade unions two weeks ago at the Centre for Nuclear Research at Saclay. The immediate aim was to protest against a plan for professional classification which would harm certain categories of personnel. In the longer term the question was that of fixing a date for a possible reorganization of the Atomic Energy Commission (the CEA). Is the CEA, which provides work for approximately 30,000 people and which, because of the size of its budget, is in French science a considerable force de frappe, threatened with disruption? In political as in research circles, many people would very much like to reduce this tremendous power by giving to various other organizations functions which originally were mistakenly attributed to the CEA for reasons which are no longer valid. The CEA, even under this system, would remain, if only for military reasons, an institution of considerable importance. Inevitably, however, a certain amount of reorganization would take place. At all events, it is doubtful whether strike action would weigh very heavily on Government decisions which will probably be taken at the highest level and in accordance with well known political and military strategy.

Despite this, another strike took place on February 20 and 21 , organized this time on a national scale by the three research workers' unions. It seems that the strike was 70-80 per cent effective. It is the mode of operation of the National Centre for Scientific Research or CNRS (6,000 research workers, 8,500 technicians) which is the issue at stake, or, rather, the method of professional promotion agreed on by the responsible ministry, the Education Ministry. Having decided to push the research workers into the industrial sector, by force if necessary, the minister, M Alain Peyrefitte, has created a bottle-neck between the first grade of the CNRS hierarchy, that of research assistant, and the second grade, that of research organizer. This year, seventy-nine assistants, all holders of doctorates and having the recommendation of the commissions concerned, have not been able to enjoy the promotion they were expecting, which is virtually forcing them to leave the CNRS once and for all.

Those who defend this measure argue that the almost automatic passing from one grade to another leads to "functionalization" of research and threatens to make the CNRS, which ought to be a dynamic body, stagnate. Their opponents, while agreeing that this argument does have some justification, deplore the improvised nature of this new policy and see in it a threat to basic research. The desire which the minister professes for "irrigating" industry is for them based on a dangerous illusion: French business men who are extremely timid in their attitude towards research are certainly disinclined to pour capital investment into this field 
and thereby offer scientists attractive posts. Furthermore, most firms are wary of research workers with a university background and prefer, when recruiting scientists, to look for them in the major colleges such as the Polytechnique or the Centrale. And university lecturing, also suggested as an alternative solution for those excluded from the CNRS, has been completely transformed in recent years, with the result that a teaching background is insisted on for lecturers. It is not at all certain that the universities will find satisfactory recruits among the members of the CNRS who had chosen precisely this field in order to pursue their work without any teaching commitments. The only course for those affected by this measurewhich from now on must be repeated year after yearseems therefore to be to yield sooner or later to the temptations of the brain drain. The American "headhunters" indeed have been making conquests in France for some time, and young people in France are beginning to have a better knowledge of English than their elders.

\section{Money and Health}

THAт the "healthiest" countries (judged in terms of mortality) spend most on health services is one of the conclusions reached in the 1967 World Health Organization report, An International Study of Health Expenditure (price 12s.) covering 29 countries. The obj-ctives of this report were two-fold: to compile comparable information on cxpenditure on health services and on methods of financing such scrvices, and to develop a standardized framework for national health accounting that could be used as a routine aid to health planning in all countries.

Most of the figures in the report were drawn from questionnaires, and the countries covered were not, it is emphasized, necessarily representative of all countries in the world because of the difficulty of obtaining information from countries with lower standards of living. Estimates of health expenditure for each country are compared with gross national product and national income.

It seems that over the period of study Israel, Canada, and the United States spent the greatest proportion of national income on health services, while the proportion of Gross National Product devoted to health services varied from 2.5 per cent to $6 \cdot 3$ per cent in countries providing full information. Countries with relatively high standards of living tended to spend more on health expenditure than countries with a lower standard of living. As the latter countries have on the whole poorer health than richer countries, less was spent both absolutely and in relation to total resources where the need was greatest.

The report states that generally there is no evidence of correlation between health expenditure and the need for health services: rather, health expenditure is prosumably influenced to a large extent by the "felt needs" of governments. No country was found in which less than 25 per cent of the money spent on health services came from public funds and among the high-income countries those receiving heaviest government support were not those allocating most money to health expenditure.

Breaking down the capital expenditure on health services, with the exception of Pakistan and France,
18 countries allocated 88 per cent or more to personal health services. Furthermore, hospitals took more than 74 per cent of capital expenditure in all countries except Chile, Czechoslovakia and Yugoslavia. The United Kingdom was well down the list with only $76 \cdot 4$ per cent provided through hospitals compared with 99.7 per cent in Canada, although a spokesman at the Ministry of Health said that 14 hospitals had in fact been built in England and Wales since 1948.

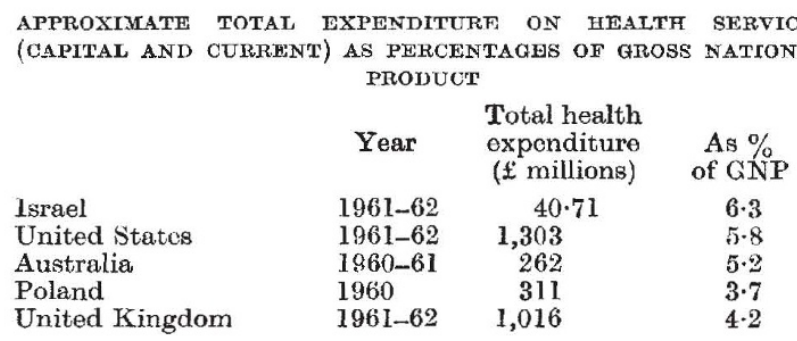

Looking to the future, until cost-benefit analysis and other techniques become applicable to the selection of targets for health programmes, the report suggests that it is desirable that the costs of health services should be consistent with a chosen long-term plan, and that the plan should be firmly based on economic realities.

\section{Developing Oxford}

\section{from our Oxford Correspondent}

As Nature went to press, Congregation at Oxford was voting on a proposal for acquiring new sites in north and central Oxford, principally for the university's scientific and administrative institutions. The administration of the university has been conducted from various buildings in different parts of Oxford, the Registry being, for example, in the Clarendon Building in the centre, while the financial department is threequarters of a mile away in Wellington Square. In 1965 , it was proposed that the Registry should expand into the premises of the nearby Indian Institute, which would then be displaced if not dismembered. Much criticism was directed at this proposal and Bodley's librarian resigned on account of it. Now, because the university has bought a number of houses around Wellington Square and also because the Franks Commission recommended that the administrative buildings should be in one place, the Hebdomadal Council has decided to apply for planning permission to redevelop Wellington Square, and move all the administrative buildings into that area. But a new Indian Institute library is already being built on top of the new Bodleian. If, then, the new proposal is accepted, all but the ground floor of the Clarendon Building and the old Indian Institute will be empty.

The council has not yet put forward suggestions for using this extremely valuable area in the centre of Oxford, considering it "premature" until planning permission has been granted for the Wellington Square development. It is possible that Hertford College will take over some of the Indian Institute building, but part at least will continue to be used as a library. Similarly, it is suggested that the Taylorian Institute and Modern Languages Faculty will take up residence in one cormer of Wellington Square, leaving another large central area empty. Here again no decision has yet been made on how to use the space. 